\title{
BIBLIOTECA MINDLIN A ALEGRIA DA PESQUISA
}

Ana Luiza Martins 
RESUMO A autora rememora as lembranças de sua experiência no convívio com Guita e José Mindlin na biblioteca pessoal do casal, hoje, Biblioteca Brasiliana Guita e José Minlin - BBM-UsP. Relembra detalhes dos aspectos físicos do espaço e menciona algumas obras e textos que eram encontrados lá e a relação de Mindlin com eles. Recorda que a biblioteca era visitada por pesquisadores acadêmicos, mas também por jornalistas, escritores, bibliófilos e estudiosos do livro e que, dessas visitas, no início, eram realizadas pesquisas informais, que, posteriormente, foram sistematizadas e organizadas com regularidade, das quais resultaram obras fundamentais para a cultura nacional.

PESQUISA - GUITA E JOSÉ

MINDLIN • BIBLIOTECA - CULTURA BRASILEIRA.

\section{THE JOY OF RESEARCHING}

ABSTRACT The author reminds the experience in the conviviality with Guita and José Mindlin at their particular library, known today as Biblioteca Brasiliana Guita e José Mindlin - BBM-USP. She remembers details about material aspects and mentions some books and texts presents there and the relation of Mindlin with them. The author evokes that the library was visited by academic researchers, but also by journalists, writers, bibliophiles and studious of the book and remembers that initially the researches were informal, but after that, it was systematized and organized with regularity and it resulted in substantial works for the national culture.

RESEARCH • GUITA E JOSÉ MINDLIN - LIBRARY - BRAZILIAN CULTURE.

\section{SOBRE A AUTORA}

Ana Luiza Martins é doutora em História Social pela FFLCH-USP. Lecionou na PUC-sp e atuou no Condephaat (Conselho de Defesa do Patrimônio Histórico, Arqueológico, Artístico e Turístico), da Secretaria da Cultura do Estado de São Paulo, de 1982 a 2015, como historiógrafa concursada, diretora de unidade e conselheira. Ocupa a cadeira n. ${ }^{\circ} 12$ da Academia Paulista de História. É autora, entre outros, de Revistas em Revista: Imprensa e Práticas Culturais em Tempos de República, São Paulo (1890-1922) (Edusp, 2001, 2ª . ed.); Gabinetes de Leitura: Cidades, Livros e Leituras na Província Paulista (Edusp, 2016); História do Café (Contexto, 2008, 3 ed.); Itaú Unibanco 90 Anos: Uma História Além dos Números (Scriptorio Comunicação, 2015). Atualmente desenvolve pesquisa residência de pós-graduação sênior na BBM-USP. 
A exemplo de José Mindlin - cujo ex-libris traz a citação de Des Livres, de Montaigne, "Ie ne fay rien sans gayeté" ("Não faço nada sem alegria") -, também nós pesquisadores éramos muito felizes naqueles idos de 1980/1990 e início de 2000, como privilegiados estudiosos na Biblioteca do Mindlin. Assim nos referíamos ao espaço mágico da Rua Princesa Isabel, n. 445, constituído pelas obras reunidas ao longo de muitos anos pelo casal Guita e José Mindlin, antes de se transformar no monumento plural da Bвм (Biblioteca Brasiliana Guita e José Mindlin) da USP, abrigado no templo arquitetônico projetado por Eduardo de Almeida e Rodrigo Mindlin Loeb.

Aliás, era o casal Guita e José que nos oferecia a sensação de intimidade e quase posse do lugar, em acolhimento generoso, franqueando mesmo seus lugares mais recônditos, para que chegássemos a bom termo nos respectivos trabalhos. Até mesmo ao chamado "Quarto do Caos", espaço diminuto em que guardavam obras a serem catalogadas. Claro que a presença de Cristina Antunes, a "guardadora de livros", tinha o condão de implementar a mágica do acolhimento perfeito, indicando títulos recém-adquiridos ou afins com as pesquisas em curso. 
Criava-se, desde sempre, a sensação dos "livros em nós” ou, como diria Mindlin, da biblioteca "que nos tem".

Esse sentimento existia sobretudo se José Mindlin estivesse presente no pavilhão - dois andares subterrâneos construídos no antigo quintal da casa, com projeto do sobrinho arquiteto Flávio Guimarães, para abrigar a ampliação da biblioteca com os títulos mais raros do país. Inclusive recebendo a especial coleção brasiliana do amigo Rubens Borba de Moraes. O lugar se transformava em palco de performances únicas do anfitrião, fosse pelas histórias rocambolescas trilhadas na garimpagem dos livros, fosse por sua inacreditável memória, quando nos recitava de cor e com expressão, desde o "Poema do Mar", do parnasiano Vicente de Carvalho, passando pelo dramático "O Corvo", de Edgar Allan Poe, finalizado solenemente em inglês com a fatal afirmativa Nevermore... Mas, também, nos levava aos risos com a graça da recitação de La Divina Increnca, de Juó Bananère, cuja pronúncia do português "macarrônico" era perfeita! Tudo isso entre as estantes vermelhas (cor preferida de Mindlin) da biblioteca do pavilhão.

Aliás, não se sabia se era uma casa-biblioteca ou se era uma biblioteca-casa. A paisagem e o cotidiano de ambas se confundiam e o acesso aos livros de uma ou outra - desde que solicitados - se tornava acessível aos interessados nas respectivas consultas. Se mencionados ao próprio Mindlin, era surpreendente sua agilidade em subir as escadas e retornar triunfante com exemplar nas mãos, possuído de uma alegria juvenil.

Sem a aura de empáfia que, em geral, envolve a figura do bibliófilo, naquele recinto de Guita e José Mindlin vivia-se a rara e deliciosa sensação de liberdade consentida aos prazeres do cultivo dos livros, quando o trabalho se tornava um brinquedo de ouro, o pote dourado do final do arco-íris. Logo, o dia de pesquisar na Mindlin se iniciava radioso! Era garimpagem de resultados inusitados, inovadores, estimulantes. Nem mesmo o trânsito - dada a distância do bairro - se apresentava capaz de abalar o humor de quem se dirigia à Biblioteca do Mindlin. E diga-se que a referência à Biblioteca do Mindlin trazia introgetada a figura de Guita, decisiva na formação do acervo e no restauro dos livros, com sua charmosa oficina implantada à esquerda da entrada da casa.

A sensação de bem-estar ocorria já na abertura do singelo portão de madeira, discreto em meio ao muro de esquina revestido de bambuzinho, que definia a esquina da Rua Princesa Isabel com a Rua Assis Brasil, no bairro do Brooklin Velho, em São Paulo. O espetáculo subsequente, do jardim bem cuidado, verdejante, definia os caminhos das bibliotecas: aquele da sala do casal, anunciado por orquídeas que floriam no tronco de uma antiga grumixama, onde estavam as primeiras obras de formação da brasiliana, com vários temas; ou aquele outro, 


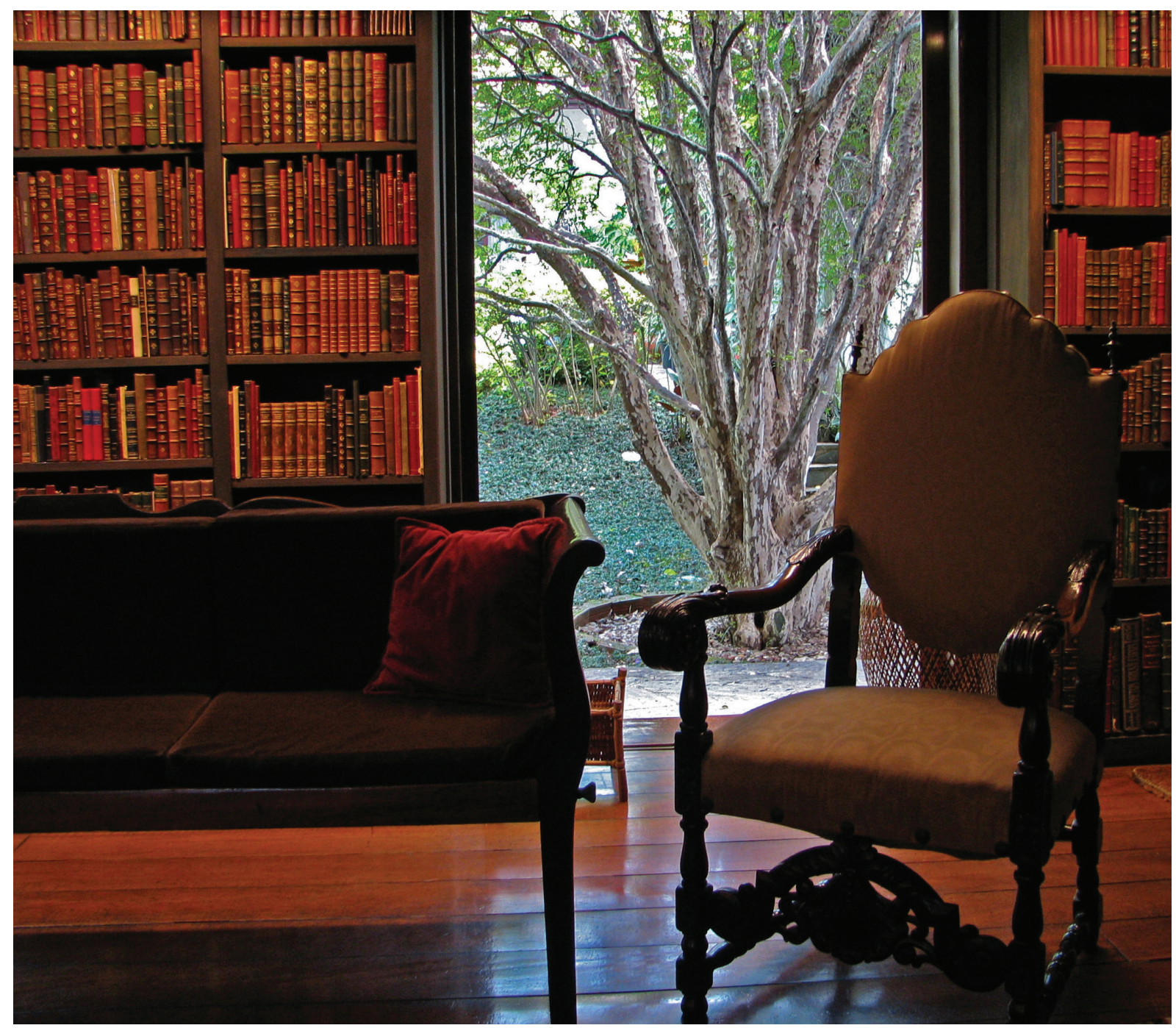

Sala da biblioteca do Mindlin com vista para a jabuticabeira. 
que dava acesso ao pavilhão, marcado por jardineiras de gerânios vermelhos nas janelas, maciços verdes de vegetação variada, finalizado por uma jabuticabeira centenária.

Pronto! Na jabuticabeira se dava o acesso à biblioteca de pesquisa - espaço de deleite absoluto - cobiçada, franqueada e frequentada por estudiosos com trabalhos de temas inusitados. Em geral eram dissertações e teses de mestrado e doutorado, que desbravavam assuntos inéditos, mas a procura do acervo se dava também por jornalistas, escritores consagrados, visitantes estrangeiros, bibliófilos e estudiosos do livro, em suas tantas dimensões.

Meus dois trabalhos acadêmicos - Gabinetes de Leitura da Província de São Paulo (1847-1890) e Revistas em Revista (1890-1922), publicados pela Edusp, só foram possíveis, pela pesquisa informal proporcionada pela Biblioteca do Mindlin, ao sabor das curiosidades e dúvidas que surgiam inesperadamente, como ocorre em pesquisas empíricas. Em todas elas, era sempre atendida com a eficiência de Cristina Antunes, ou mesmo pelo próprio José Mindlin. Esse, aventando a possibilidade de algum título de nosso interesse nos escapar, caminhava conosco até a "Dona Rosa”, a casa vizinha da Rua Assis Brasil, onde alugara algumas salas para guarda de livros e revistas por organizar. A interlocução pelo meio do caminho suscitava mais conhecimento e muita curiosidade. Era uma delícia!

A despeito da ordem absoluta do pavilhão e do silêncio que imperava no recinto - postulado de toda a biblioteca - vivia-se ali a sensação de total liberdade, até porque, em nossas pausas para espairecer, percorríamos livremente os corredores das estantes e viajávamos na sequência de títulos raros, na beleza das lombadas ou mesmo dos exemplares dos livros de D. Pedro II, expondo as capas de veludo com letras douradas encimadas pela coroa imperial; ou aqueles imensos álbuns dos viajantes dos séculos XVIII e XIX, que abertos se desdobravam em viagens pelo Brasil profundo secular. Com cuidado, podíamos apanhá-los, tocá-los, conhecê-los.

Encontrar ali pesquisadores às voltas com trabalhos afins ou díspares era motivo para se estabelecer relações, descobrir afinidades eletivas, que se desdobraram pela vida afora. Em geral, essas aproximações, no meu caso, foram muito proporcionadas por Mindlin, que sabia das pesquisas em curso na biblioteca e unia pesquisadores com similaridades de temas e mesmo de temperamentos. Por conta disso, num dia comum, fui chamada intempestivamente para almoçar com João Alexandre Barbosa, comensal da família Mindlin, que em clima de absoluta informalidade, entre os pratos da maravilhosa cozinheira Catarina, me instigou para novas questões do trabalho em curso. 
Havia também alguns sustos: numa manhã, em que cheguei bem cedo, percorrendo as estantes, quase tropecei num corpo humano deitado, que tentava divisar títulos de lombadas das prateleiras mais baixas. Era Ruy Sousa e Silva, advogado e bibliófilo, que naquela altura garimpava, junto com Pedro Corrêa do Lago, os livros que formariam a Brasiliana Itaú. Por ser muito alto, só mesmo quase deitado conseguia de uma só vez ter acesso aos títulos das prateleiras baixas, quase ao nível do solo, não obstante toda a biblioteca já estar catalogada em método singular, definido por Mindlin e Cristina Antunes.

Era assim a Biblioteca do Mindlin, ainda nada virtual - apesar de já lançar-se nos primeiros passos da informática. Era a possibilidade de ver o livro de perto, tocá-lo, surpreender-se com suas capas, ter a real dimensão do tamanho, sentir a gramatura do papel, o perfume dos séculos, enfim, conhecer efetivamente a publicação rara. Ou melhor, o tesouro, que se manuseava com reverência.

Uma das práticas possíveis era ter sobre a mesa de trabalho vários exemplares de títulos diversos, que permitiam cotejos e leituras simultâneas, esclarecedores de dúvidas e passíveis de apreensão mais ampla dos assuntos pesquisados e das respectivas publicações. Nada mais restritivo ao estudioso, para efeitos de comparação formal e cotejo das matérias, que confiná-lo a exemplares limitados. A restrição tolhe e bloqueia voos mais altos do conhecimento e da imaginação, sempre necessários para o melhor domínio do assunto e do conteúdo pretendidos. Assim, a pesquisa indisciplinada da indisciplinada biblioteca de Mindlin rendia frutos incalculáveis. Aliás, nada mais avesso à indisciplina que a ordem reinante no recinto, absoluta na distribuição das estantes, na organização dos títulos, na higienização constante das obras.

A evocação de memórias dos tempos de pesquisa na Biblioteca do Mindlin da Rua Princesa Isabel poderia ir longe, tantas eram as situações sempre inusitadas de cada dia de pesquisa. Só mais uma: belo dia surgiu no pavilhão uma personagem nova. Era Elisa Nazarian, livreira experiente, que se envolveu com a correspondência que nascera por causa e em torno da biblioteca. Também ela, ciente das pesquisas em curso, não se furtava em compartilhar com os pesquisadores as informações de interesse descobertos nos bilhetes, cartas, anotações, textos manuscritos, situando os interlocutores que interagiram com Guita e José Mindlin. Impossível também não lembrar de Rosana Gonçalves, a quem Mindlin nomeou "a achadora oficial da Biblioteca”, pelo seu faro em localizar algum título desgarrado; e de Sérgio Pizoli, às voltas com o acervo de gravuras e iconografia da biblioteca.

Mas é hora de estar alerta às epígrafes de Claudio Giordano - bibliófilo atilado e amigo muito próximo de José Mindlin - citando o 
Eclesiastes: "Fazer livros, filho meu, é um trabalho sem fim”. Também é tarefa sem fim rememorar os tempos da Biblioteca do Mindlin, da Rua Princesa Isabel. Convém, portanto, parar por aqui, nesse passeio de saudade e registro de um tempo feliz.

Importa lembrar, contudo, que daquelas pesquisas iniciadas informais, a princípio franqueadas para um ou outro pesquisador, mas depois sistematizadas e organizadas com regularidade a tantos interessados, resultaram obras decisivas da cultura nacional. Impossível não rememorar os tantos prêmios Jabuti que nasceram daquelas salas, muitos deles editados pela Edusp, sob a presidência de Plinio Martins Filho. Lembro-me vivamente de Carlos Eugênio Marcondes de Moura, meu contemporâneo naqueles tempos de pesquisa no Mindlin, figura que impressionava pela assiduidade e obsessão no foco do trabalho. Indiretamente germinou ali a obra que lhe daria a honra do Prêmio Jabuti de 2013: Estou Aqui. Sempre Estive. Sempre Estarei: Indígenas do Brasil. Suas Imagens (1505-1955)ํ․ Tudo começou lá na Biblioteca do Mindlin.

Hoje, a "biblioteca do imigrante", como a tachou a filha Betty Mindlin, historiando a ancestralidade dos pais, "judeus fugitivos da perseguição e do preconceito na Europa Oriental”", figura como brasiliana excepcional, implantada no campus da usP, ampliando as possibilidades de pesquisa e ações culturais. Pratica-se ali a concepção de Mindlin, para quem a biblioteca devia ser um organismo vivo, pulsante, e não algo com ponto final. Razão pela qual a Brasiliana cresce e se dinamiza, comportando reserva técnica com espaço para noventa mil novos livros e prateleiras vazias no aguardo de novos títulos.

No presente, é inevitável constatar-se a oposição dos cenários e das práticas de acesso e consulta entre a morada aconchegante da Rua Princesa Isabel e o edifício quase palaciano implantado na USP. Neste - pois de rigor numa biblioteca institucional - há censores, guardas e todo um aparato de segurança necessário, que se faz efetivamente presente. Todavia, a despeito da materialidade oficial do edifício, tem-se no térreo e na visão do acervo envidraçado na parte superior do pé-direito do saguão de acesso, as tantas histórias da "biblioteca indisciplinada", fruto da "loucura mansa" de seu formador. Assim como em seu interior é quase possível se deparar com sua presença ao atravessar áreas definidas por frases de Mindlin, dotadas de humor e evocativas da aquisição rocambolesca de muitas das obras.

1. Carlos Eugênio Marcondes de Moura, Estou Aqui. Sempre Estive. Sempre Estarei: Indígenas do Brasil. Suas Imagens (1505-1955), São Paulo, Edusp, 2012.

2. Betty Mindlin, Crônicas Despidas e Vestidas, São Paulo, Contexto, 2017, p. 208. 
É a biblioteca que pulsa de histórias e estórias, aguça a busca da informação, estimula o cultivo do livro. Importa viver nela a sensação de liberdade na pesquisa e o acesso generoso a seu acervo, indutores dos voos da imaginação e da criatividade na maravilhosa aventura da produção do conhecimento. 